\title{
c-FOS suppresses ovarian cancer progression by changing adhesion
}

\author{
L Oliveira-Ferrer ${ }^{1,5}$, K Rößler $^{1,5}$, V Haustein ${ }^{1}$, C Schröder ${ }^{2}$, D Wicklein ${ }^{2}$, D Maltseva ${ }^{3}$, N Khaustova $^{3}$, \\ T Samatov ${ }^{3}$, A Tonevitsky ${ }^{4}$, S Mahner ${ }^{1}$, F Jänicke ${ }^{1}$, U Schumacher ${ }^{2}$ and K Milde-Langosch ${ }^{*}, 1$ \\ ${ }^{1}$ Department of Gynecology, University Medical Center Hamburg-Eppendorf, Martinistr. 52, D-20246, Hamburg, Germany; \\ ${ }^{2}$ Department of Anatomy and Experimental Morphology, University Medical Center Hamburg-Eppendorf, Martinistr. 52, D-20246, \\ Hamburg, Germany; ${ }^{3}$ SRC Bioclinicum, Ugreshskaya Street 2/85, Moscow 115088, Russia and ${ }^{4}$ Institute of General Pathology and \\ Pathophysiology, Baltijskaya Street 8, Moscow 125315, Russia
}

Background: C-Fos was initially described as oncogene, but was associated with favourable prognosis in ovarian cancer (OvCa) patients. The molecular and functional aspects underlying this effect are still unknown.

Methods: Using stable transfectants of SKOV3 and OVCAR8 cells, proliferation, migration, invasion and apoptotic potential of c-FOS-overexpressing clones and controls were compared. Adherence to components of the extracellular matrix was analysed in static assays, and adhesion to E-selectin, endothelial and mesothelial cells in dynamic flow assays. The effect of c-FOS in vivo was studied after intraperitoneal injection of SKOV3 clones into SCID mice, and changes in gene expression were determined by microarray analysis.

Results: Tumour growth after injection into SCID mice was strongly delayed by c-FOS overexpression, with reduction of lung metastases and circulating tumour cells. In vitro, c-FOS had only weak influence on proliferation and migration, but was strongly pro-apoptotic. Adhesion to components of the extracellular matrix (collagen I, IV) and to E-selectin, endothelial and mesothelial cells was significantly reduced in c-FOS-overexpressing OvCa cells. This corresponds to deregulation of adhesion proteins and glycosylation enzymes in microarray analysis.

Conclusion: In addition to its known pro-apoptotic effect, c-FOS might influence OvCa progression by changing the adhesion of OvCa cells to peritoneal surfaces.

Ovarian carcinoma is mostly diagnosed in advanced stages when intraperitoneal metastasis has already taken place. Up to now, therapy is based on optimal surgical tumour reduction (debulking) followed by platin-based combination chemotherapy. In spite of intensive research, there are no established molecular prognostic or predictive markers for this cancer type, and new molecular targets for an individualised therapy are urgently needed.

In search for new markers, we found that against expectation, high c-FOS protein expression in tumour tissue was associated with a significantly prolonged recurrence-free and overall survival and had an independent favourable impact on tumour progression (Mahner et al, 2008). c-FOS encodes a transcription factor of the activating protein-1 (AP-1) family which, after dimerisation with one of the Jun proteins, participates in regulation of a variety of genes, partly involved in tumour growth and progression (Durchdewald et al, 2009). First identified because of its homology to the retroviral oncogene $v$-fos which induces murine osteogenic sarcomas, human c-FOS causes osteosarcomas in transgenic mice (Rüther et al, 1989) and is able to transform rodent fibroblasts (Miller et al, 1984).

In humans, an oncogenic function of c-FOS was proposed in tumours of the bone (Gamberi et al, 1998), skin (Guinea-Viniegra et al, 2012), brain (Silvestre et al, 2010) and lung (Volm et al, 2002). Yet, in murine mammary carcinoma cells c-FOS was found

\footnotetext{
${ }^{*}$ Correspondence: Dr K Milde-Langosch; E-mail: milde@uke.de

${ }^{5}$ These authors contributed equally to this work.
}

Received 7 August 2013; revised 7 November 2013; accepted 13 November 2013; published online 5 December 2013 
only in non-metastatic cells, whereas Fra-1 and Fra-2 dominated in metastatic descendants (Kustikova et al, 1998). In the last years, the idea of c-FOS as a Janus-type regulator (Durchdewald et al, 2009) with possible tumour-suppressor qualities emerged. c-FOS inhibits proliferation of neoplastic hepatocytes (Mikula et al, 2003), is decreased in thyroid tumours (Liu et al, 1999) and has a positive prognostic impact in gastric cancer (Jin et al, 2007). In ovarian cancer (OvCa), high c-FOS expression correlated with a welldifferentiated phenotype (Meinhold-Heerlein et al, 2005), is reduced in metastases compared with primary tumours (Hein et al, 2009), and an independent favourable prognostic marker (Mahner et al, 2008).

In order to further investigate the tumour-suppressor effect of c-FOS in ovarian carcinomas, we performed functional assays and in vivo tests using OvCa cells with stable c-FOS overexpression. Our results point to a strong influence of c-FOS on cell adhesion and provide an explanation for the favourable prognostic impact of this protein in clinical OvCa.

\section{MATERIALS AND METHODS}

Cell lines and stable transfections. The human OvCa cell lines SKOV3 (obtained from American Type Culture Collection, Manassas, VA, USA) and OVCAR8 (a kind gift of Dr Volker Assmann, Institute of Tumor Biology, Hamburg, Germany) were cultivated as described (Hein et al, 2009). The full c-Fos cDNA which had been cloned into the pcDNA3.1 + plasmid (Nandy et al, 2003) was subcloned in the bicistronic vector pIRES-P (Genbank no. Z75185) using NheI and EcoR1 restriction enzymes.

Transfections with this plasmid and the empty vector were performed with Lipofectamin (Invitrogen GIBCO/Life Technologies, Carlsbad, CA, USA). After selection with puromycin the single-cell clones SKOV3-c-FOS\#1 and \#6 and OVCAR8-c-FOS\#5 and \#7 were chosen for further analysis. As negative controls transfectants with the empty vector were generated. The differences in c-FOS expression were repeatedly confirmed by western blots during the experiments (Figure 1A).

Human pulmonal microvascular endothelial cells (HPMEC, PromoCell, Heidelberg, Germany) and human adult mesothelial cells (MES, ZenBio, Research Triangle Park, NC, USA) were cultivated as recommended by the suppliers.

Western blot analysis and uPA-ELISA. Protein extraction and western blot analysis were performed as described (Hein et al, 2009 ) with the following antibodies: c-FOS polyclonal antibody 4 (1:1000; Santa Cruz Biotechnology, Heidelberg, Germany), CHST11 monoclonal antibody ab57225 (1:200; Abcam, Cambridge, UK), osteopontin (SPP1) monoclonal antibody sc-21742 (1:1000; Santa Cruz Biotechnology), sLe ${ }^{\mathrm{a}}$ (KM231) monoclonal antibody (1:200; EMD Millipore, Billerica, MA, USA) and $\beta$-ACTIN monoclonal antibody (1: 1000; Santa Cruz Biotechnology). Urokinase-type plasminogen activator (uPA) in cell extracts was quantified by ELISA as described (Jänicke et al, 1994).

Proliferation assay. Cell proliferation was analysed using the Cell Proliferation Kit I (MTT) (Roche Applied Science, Mannheim, Germany) in medium containing $1 \%$ and $10 \%$ FCS. Cells were seeded into the wells of 96-well-plates at 5000 cells in $100 \mu \mathrm{l}$ per well, and cell growth was determined after 24 and $72 \mathrm{~h}$.

Apoptosis assay. Apoptotic cells were detected using the M30 cytoDEATH antibody (Roche Applied Science). Cells were incubated with normal medium or $0.4 \mu \mathrm{g} \mathrm{ml}^{-1}$ camptothecin for $16 \mathrm{~h}$, and transferred to glass slides by a cytocentrifuge (200 000 cells per slide). Alternatively, cells were grown on FALCON 8 -chamber culture slides at $3 \times 10^{4}$ cells per chamber (Becton Dickinson, Franklin Lakes, NJ, USA). After fixation with ice-cold
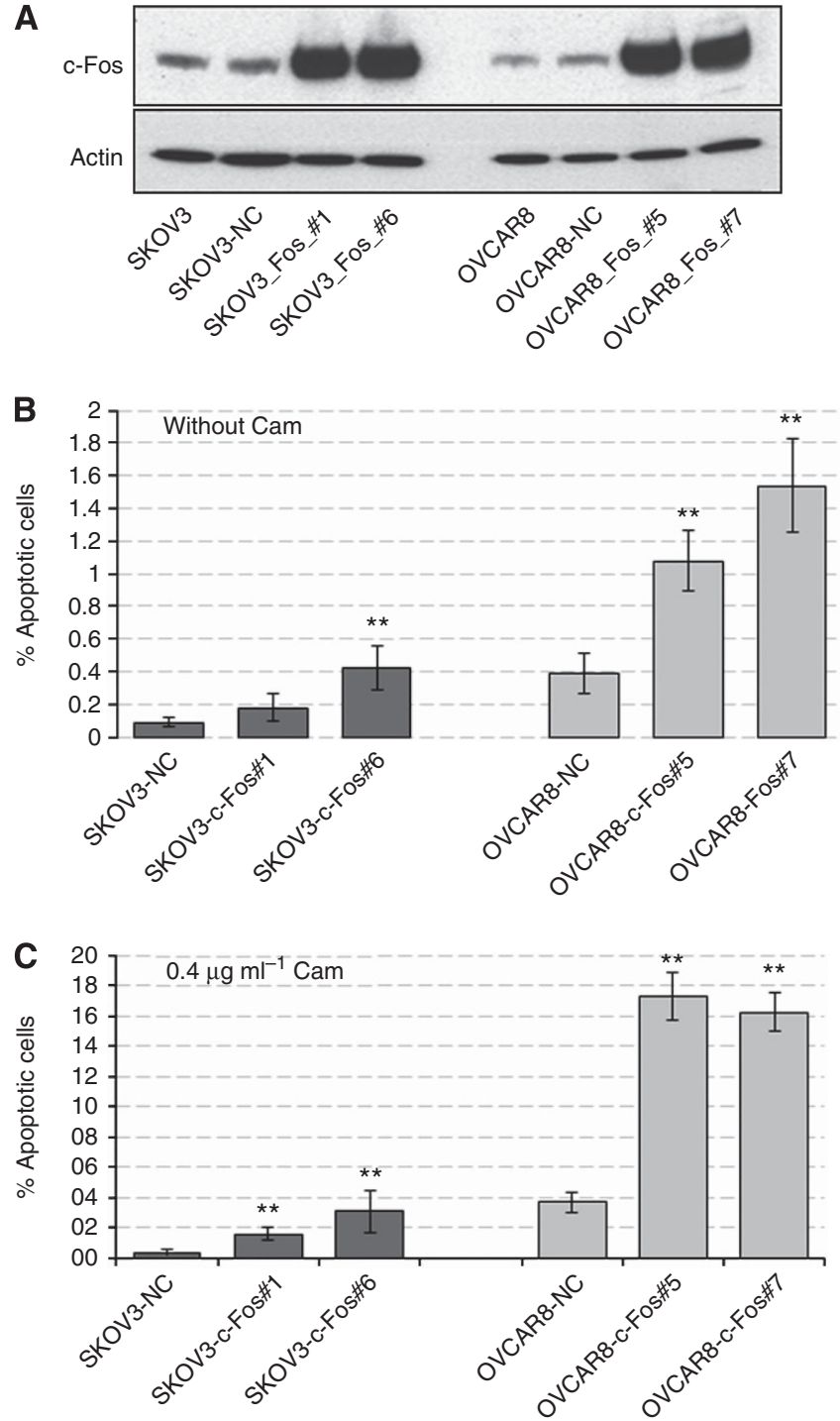

Figure 1. Influence of c-Fos overexpression on the apoptotic potential of SKOV3 and OVCAR8 cells. (A) Western blot analysis showing c-FOS expression in stably transfected clones derived from SKOV3 and OVCAR8 cells as compared with untransfected cells and cells transfected with the empty vector (NC). As control, ACTIN expression is shown. (B and $\mathbf{C})$ Apoptotic SKOV3 and OVCAR8 cells without (B) and with addition of $0.4 \mu \mathrm{g} \mathrm{ml}^{-1}$ Camptothecin (C). M30-positive cells were counted in 700-4000 cells in three experiments, performed in triplicate. Mean percentages of apoptotic cells \pm s.e.m. are shown. Asterisks indicate significant difference compared with corresponding control (NC) cells: ${ }^{\star *} P<0.01$.

methanol and incubation with the M30 antibody $(1: 20)$, detection with anti mouse IgG (Vectastain, Vector Laboratories, Burlingame, CA, USA) and the ABC-AP complex (Vector Laboratories) was performed. Percentages of stained cells were determined by microscopy in at least 800 cells.

Invasion and motility assays. The invasive potential of the cells was tested with Matrigel TM Invasion Chambers (BD Biosciences, Heidelberg, Germany) as previously described with 25000 cells per chamber and 24-h incubation for OVCAR8 and 12500 cells and 12-h incubation for SKOV3 (Hein et al, 2009). Invading cells were counted by microscopy at $\times 100$ magnification in five visual fields including most of the membrane area. Motility was analysed using a wound-healing assay as described (Hein et al, 2009). 
Static cell adhesion assay. Ninety-six-well plates were coated overnight with $50 \mu \mathrm{l}$ protein solutions in $0.02 \mu \mathrm{g} \mu \mathrm{l}^{-1}$ concentration of collagen I (Roche Diagnostics $\mathrm{GmbH}$, Grenzach-Wyhlen, Germany), collagen IV (Sigma-Aldrich, Hamburg, Germany), fibronectin (Harbor Bio-Products, Norwood, MA, USA) or vitronectin (R\&D Systems, Minneapolis, MN, USA) while laminin (Sigma-Aldrich) was used at $0.1 \mu \mathrm{g} \mu \mathrm{l}^{-1}$. Cells were adjusted to $10^{6}$ cells $\mathrm{ml}^{-1}$ and $100 \mu \mathrm{l}$ of the suspension were pipetted into each well, incubated for $20 \mathrm{~min}$ at $37^{\circ} \mathrm{C}$, washed with PBS and fixed with $4 \%$ paraformaldehyde for $30 \mathrm{~min}$. After staining with $0.1 \%$ gentiana violet for $15 \mathrm{~min}$, washing and addition of $100 \mu \mathrm{l}$ Triton X-100 per well, extinction at $540 \mathrm{~nm}$ was measured in a plate reader.

Dynamic cell flow adhesion assay. Cell adhesion under flow conditions was analysed with ibiTreat slides (IBIDI, Martinsried, Germany) as described (Richter et al, 2011; Dippel et al, 2012). The channels of these slides were coated with rhE-selectin $\left(0.25 \mu \mathrm{g} \mu \mathrm{l}^{-1}\right.$; R\&D Systems), HPMEC or MES. For HPMEC or MES, 80000 cells per channel were seeded and cultivated until confluence for about $48 \mathrm{~h}$. Then they were stimulated with TNF-alpha $\left(10 \mathrm{ng} \mathrm{m}^{-1}\right)$ for $4 \mathrm{~h}$ which had been previously shown to be the optimal activation period (Dippel et al, 2012). Ovarian cancer cells were adjusted to $10^{5}$ cells $\mathrm{ml}^{-1}$ in serum-free medium. The perfusion pump created a constant flow of the cell suspension through the flow chamber of $4.2-16.8 \mathrm{ml} \mathrm{h}^{-1}$, corresponding to a shear stress of $0.125-0.5$ dyn $\mathrm{cm}^{-2}$ or $0.0125-0.05 \mathrm{~Pa}$. Cell adhesion was digitally recorded for 1-2 min by a video camera mounted on the microscope. Adherent cells were counted using CapImage software (Dr Zeintl, Heidelberg, Germany) and given as percentage of adherent control cells per minute.

Flow cytometry. For assessment of selectin ligand structures CD15s (sialyl LewisX) and CA19-9 (sialyl LewisA), tumour cells were incubated with unconjugated antibodies against CD15s (BD Bioscience, Heidelberg Germany), CA19-9 (Abcam, Cambridge, MA, USA) or the isotype control IgM (Dako Denmarck A/S, Glostrup, Denmark) and detected with allophycocyanin-conjugated goat anti-mouse Ig (BD Biosciences). CD15s and CA19-9 were analysed in OVCAR8 cells subjected to shear forces as well. Briefly, cells were collected after cell flow $\left(0.25 \mathrm{dyn} \mathrm{cm}^{-2}\right)$ on slides coated with FCS, fixed with $1 \%$ PFA for $10 \mathrm{~min}$ and stained as mentioned above. For detection of $\beta 1$ and $\beta 4$ integrin subunits, FITC-conjugated monoclonal CD29 antibody (eBioscience, San Diego, CA, USA) and eFluor 660-conjugated CD104 antibody (eBioscience) as well as the corresponding isotype controls mouse IgG1-FITC (MACS, Miltenyi Biotec GmbH, Bergisch Gladbach, Germany) and rat IgG2K-eFluor 660 (eBioscience) were used. Cells were incubated with FITC-conjugated monoclonal MAB1976F antibody or FITC mouse IgG as isotype control (B\&D Bioscience) for detection of the integrin receptor complex av $33.1: 200$; EMD Millipore, Billerica, MA). Stained cells were analysed using a FACSCalibur cytometer (BD Biosciences).

Xenograft model for intraperitoneal tumour growth. Animal experiments were conducted according to the UKCCR guidelines for the welfare of animals in experimental neoplasia (Workman et al, 2010). For injection into SCID mice, SKOV3-NC and -c-FOS\#1 cells were adjusted to $5 \times 10^{6} \mathrm{ml}^{-1}$ in RPMI medium. In all, $200 \mu \mathrm{l}$ of that suspension was injected into the peritoneal cavity of female mice (10 animals per group). Mice that showed strong signs of tumour progression (ascites, shaggy coat and loss of appetite; Workman et al, 2010) were killed. Tumours at the injection site, metastases and lungs were excised, frozen or formalin-fixed and embedded in paraffin.

Metastatic cells in mouse lungs were counted as previously described (Jojovic and Schumacher, 2000). Sections of paraffinembedded tumour tissues were also stained with antibodies against c-FOS (c-FOS polyclonal antibody 4; Santa Cruz Biotechnology;
1:150) and Ki67 (Dako) as described (Mahner et al, 2008; Oliveira-Ferrer et al, 2012) as well as Versican (VCAN polyclonal antibody ab28671; $1: 50$; Abcam).

For further detection of circulating tumour cells (CTCs), terminal cardiac puncture blood collection was performed. DNA extraction from mouse blood and qRT-PCR with primers specific for human ALU sequences were performed as described (Stübke et al, 2012).

Microarray analysis. RNA isolation and quality controls from SKOV3 and OVCAR8 clones and frozen tumour samples as well as microarray analysis of SKOV3 clones were performed as described (Schröder et al, 2010). For OVCAR8 cells and tumour samples, procedures for cDNA synthesis and labelling were carried out according to the Ambion WT Expression Kit (Life Technologies, Darmstadt, Germany) using $500 \mathrm{ng}$ total RNA as starting material. These experiments were performed using Affymetrix Human Gene 1.0 ST Array (Affymetrix Inc., Santa Clara, CA, USA) and statistical analysis was performed using bioconductor package limma. The Benjamini-Hochberg algorithm was used for multiple testing adjustments. Bioinformatic analysis was done using DAVID tool.

qRT-PCR and glycosylation PCR-Array for validation of gene expression data. RNA extraction and quality analyses were performed as mentioned above. RNA was reverse transcribed using the Transcriptor First Strand Synthese Kit (Roche, Basel, Switzerland). Quantitative RT-PCR analysis was carried out on the capillary-based Light Cycler (Roche) using the SYBR Premix Ex Taq (Takara, Saint-Germain-en-Laye, France). Samples were analysed in triplicate and averaged. Target genes were normalised to the reference gene glycerinaldehyde-3-phosphate dehydroxygenase and data were analysed based on the $\Delta \Delta C_{\mathrm{t}}$ method. Primers are shown in Supplementary Table S1. Quantitative PCR analysis of glycosylation key genes was assessed with the Human Glycosylation $\mathrm{RT}^{2}$ Profiler PCR Array (SA Biosciences, Qiagen, Hilden, Germany) as described (Lange et al, 2012).

Statistics. Differences between c-FOS-overexpressing and control clones in functional assays (at least three independent tests, performed in triplicate) were evaluated by two-sided T-tests, ANOVA analysis (dynamic adhesion assays) or a linear mixed model (static adhesion assays) using the SPSS20 program (IBM, Ehningen, Germany). Survival of SCID mice was analysed by Kaplan-Meier analysis and log-rank test. $P$-values $<0.05$ were regarded as statistically significant.

\section{RESULTS}

Effect of c-FOS overexpression on proliferation, motility and invasive potential of OvCa cells. In order to analyse the functional role of c-FOS in OvCa cells, we established stable transfectants with overexpression of the transcription factor in two OvCa cell lines. High c-FOS expression levels could be confirmed in two single-cell clones of either SKOV3 (c-FOS\#1 and c-FOS\#6) and OVCAR8 (c-FOS\#5 and c-FOS\#7) cells by western blot analysis (Figure 1A). The effect of c-FOS overexpression on cell growth was examined in normal growth medium and under serum-reduced conditions. Although high c-FOS levels did not affect SKOV3 proliferation, it significantly increased OVCAR8 cell growth under normal conditions. In contrast, c-FOS-overexpressing $\left(c-\right.$ FOS $\left.^{\text {high }}\right)$ cells cultured in serum-reduced media, which better mimics the situation in vivo, demonstrated lower proliferation rates in both cell lines when compared with mock transfected (Supplementary Figure S1A). In an in vitro wound-healing assay, ${\mathrm{c}-F O S^{\text {high }}}$ clones showed a significantly retarded wound closure by $15 \%$ to $35 \%$ compared with control cells. The invasive capacity of 
the clones was further tested using Matrigel invasion chambers. Surprisingly, OVCAR8 and SKOV3 cells exhibited an oppositional behaviour under c-FOS influence. c-FOS overexpression endowed the SKOV3 cells with a higher invasive phenotype, whereas a strong decrease in invasion of c-FOS ${ }^{\text {high }}$ OVCAR8 cells compared with control cells was observed (Supplementary Figure S1).

c-FOS overexpression increases the apoptotic potential of OvCa cells. As c-FOS has been implicated in the regulation of apoptosis (Shaulian and Karin, 2001), we performed immunohistochemical M30 cytoDeath antibody staining after normal culture conditions and after exposure to the cytotoxic agent camptothecin, which is an alkaloid and anticancer agent that inhibits DNA topoisomerase. Quantification of apoptotic cells revealed enhanced apoptosis in c-FOS-overexpressing cells compared with control cells (2.0- to 4.8-fold) under normal culture conditions (Figure 1B). As expected, there was a higher frequency of apoptotic cells after treatment with camptothecin. Remarkably, a 4.4 - to 10.3 -fold increase of apoptotic cells in c-FOS ${ }^{\text {high }}$ cultures in comparison with controls was observed (Figure 1C).

c-FOS overexpression inhibits tumour growth and metastasis in an intraperitoneal xenograft model of human OvCa. To further investigate the effects of c-FOS on tumour growth in vivo, we chose the highly aggressive and metastatic SKOV3 cell line. Cells with c-FOS overexpression (c-FOS\#1) as well as control cells (NC) were injected intraperitoneally into SCID mice (10 mice per group). Mice with transplanted SKOV3-NC cells had to be killed according to previously defined criteria (Workman et al, 2010) after 63 days. In contrast, the group with c-FOS ${ }^{\text {high }}$ tumours $(n=9$; one died for unknown reason) showed symptoms of intraperitoneal tumour growth 162 days after injection (Figure 2A). Necropsy of the mice confirmed intraperitoneal carcinomatosis in all animals and tumours at the injection sites in all but four mice (1 SKOV3-NC, 3 SKOV3-c-FOS). Excised tumours were weighed $(0.26-0.61 \mathrm{~g}$ for SKOV3-NC; $0.33-0.70 \mathrm{~g}$ in SKOV3-c-FOS mice) and analysed immunohistochemically to corroborate the differences in c-FOS expression in vivo (Figure 2B; upper panels). High percentages of Ki67-stained nuclei were found in both groups of tumours (Figure 2B, lower panels). Interestingly, we observed cells with huge polyploid nuclei in some tumours of the c-FOS ${ }^{\text {high }}$ group (lower panel; arrow). Further, we did not find significant differences in the amount of apoptotic cells between control and c-FOS $^{\text {high }}$ tumours (data not shown).

To examine the effect of c-FOS on the metastatic potential of SKOV3 cells, we quantified tumour cell dissemination in blood and lungs from SKOV3-c-FOS ${ }^{\text {high }}$ and control mice using Alu-PCR and microscopic examination, respectively. Human Alu repeat DNA corresponding to an average of $1.3 \times 10^{5}$ CTCs per ml blood was detectable in the control group versus 44 CTCs in the c-FOS group (median values 30000 vs 18 cells ml $^{-1} ; P=0.056$; Figure 2C). Pulmonary micrometastases quantified by microscopic examination were found in all SKOV3-NC injected mice with an average of 5.8 micrometastases consisting of 1-20 vital tumour cells per section. In contrast, SKOV3-c-FOS\#1 injected mice evidenced minimal lung metastasis (mean 0.5 metastases per section; $P=0.030$; Figure 2D). By Spearman-Rho test, a strong correlation of lung micrometastasis and circulating DNA was found $(P<0.001$; data not shown).

c-FOS reduces adherence to ECM components in OvCa cells. As cell-cell and cell-matrix interactions have an essential role in tumour growth and metastasis, we further studied the potential effect of c-FOS on the adhesive properties of OvCa cells.
A
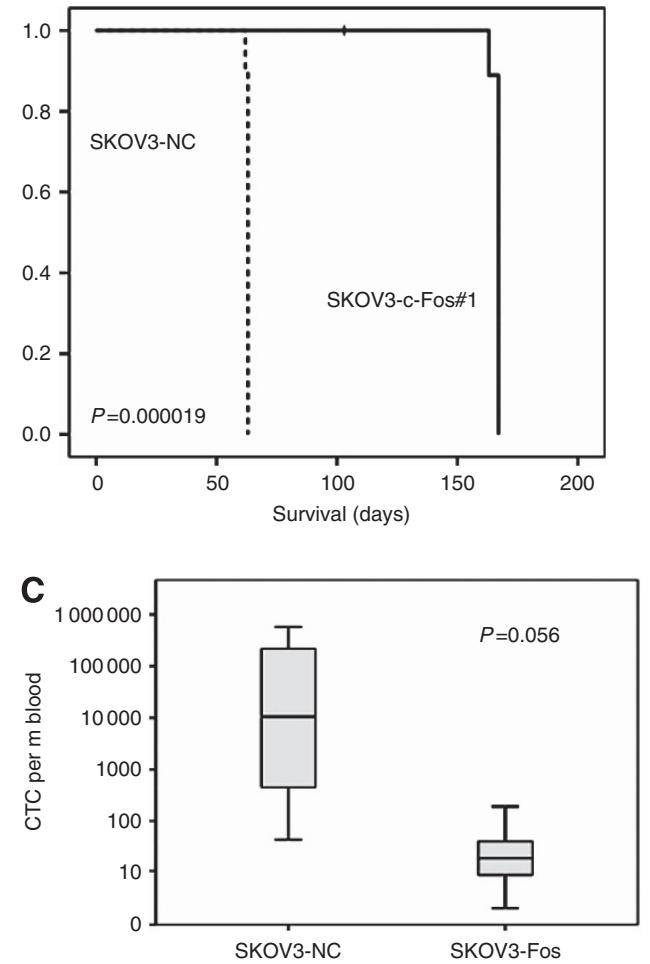

B
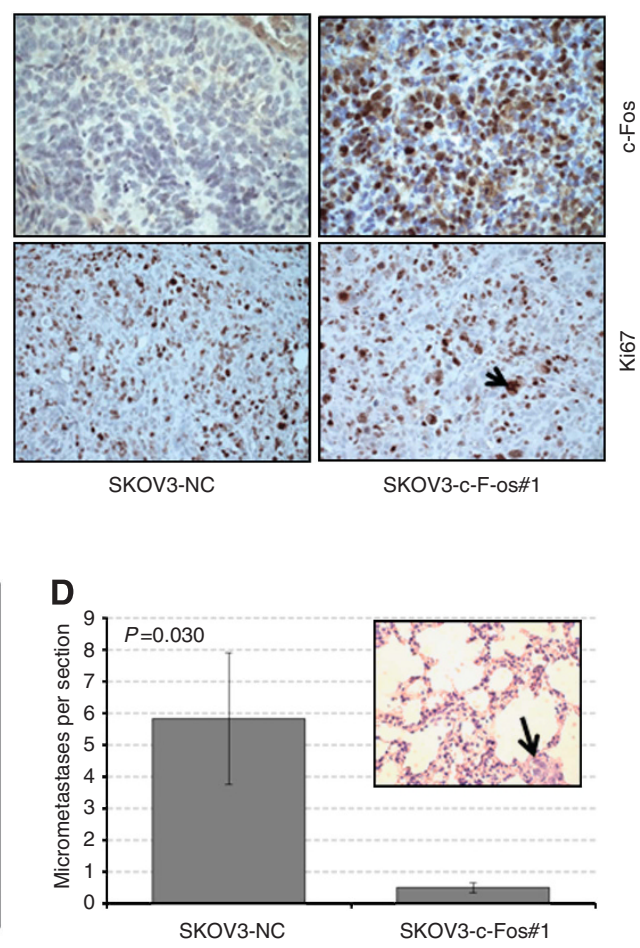

Figure 2. Tumour growth and metastasis after intraperitoneal injection of SKOV3 (A-D) into SCID mice ( $n=10$, each group) (A) Kaplan-Meier analysis showing survival of SCID mice after injection of SKOV3-NC or SKOV3-c-FOS\#1cells. (B) c-FOS and Ki67 immunohistochemistry in paraffin sections of representative SCID mouse tumours ( $\times 400)$. The arrow indicates example of a large, polyploidy nucleus found in tumours with c-FOS overexpression. (C) Results of Alu-PCR for detection of human DNA in mouse blood. (D) Detection of tumour cells in paraffin sections of mouse lungs (mean number of vital tumour cells per paraffin section \pm s.e.m.). Insert shows a representative micrometastasis in a lung section (arrow). 
First, we performed static adhesion assays on the stromal ECM proteins, type I collagen, fibronectin and vitronectin, and the basement membrane proteins, type IV collagen and laminin. Interestingly, c-FOS overexpression resulted in a significantly reduced adhesion to collagen I and collagen IV-coated surfaces in both cell lines. OVCAR8 and SKOV3 cells with enhanced c-FOS expression also showed weakly decreased binding to laminin and vitronectin (Figures $3 \mathrm{~A}$ and $\mathrm{B}$ ), whereas adhesion to fibronectin was not influenced (data not shown).

In order to find out if the reduced adhesion to ECM proteins is caused by changes in their integrin ligands, we analysed expression of various integrin monomers and dimers by flow cytometry. Expression of integrin $\beta 1$, which is involved in collagen binding in various heterodimeric combinations, was reduced by c-FOS overexpression in both cell lines (Figure 3C). In contrast, integrin $\beta 4$ that is part of laminin-binding heterodimers, was downregulated by c-FOS in SKOV3 (Figure 3C), but not in OVCAR8 cells (data not shown). The heterodimer $\alpha \mathrm{V} \beta 3$ integrin that binds to various ligands including vitronectin and fibronectin was strongly reduced in c-FOS-overexpressing SKOV3 clones (Figure 3C), whereas its $\beta 3$ subunit itself was only weakly downregulated in both cell lines (data not shown). The vitronectin-binding heterodimer $\alpha \mathrm{V} \beta 5$ was only weakly expressed in both cell lines and not significantly changed by c-FOS (data not shown).

c-FOS regulates E-selectin binding under physiological flow conditions. Selectins have been implicated to have an essential role during metastatic spread in different tumour entities (Barthel et al, 2007). Particularly, E-selectin is expressed in activated endothelial cells and has been also detected on the mesothelial cell surface (Gebauer et al, 2012). Hence, we evaluated the influence of c-FOS on OvCa cell adhesion to E-selectin under dynamic conditions.

In the laminar flow chamber assay with E-selectin-coated surfaces, SKOV3 and OVCAR8 cells showed firm adhesion events as well as rolling behaviour, which were not differentiated for overall quantitative evaluation. Cell adhesion or tethering was not observed when capillaries were coated with fetal calf serum, used as negative control (data not shown). At shear rates of $0.5 \mathrm{dyn} \mathrm{cm}^{-2}$, only one OVCAR8 c-FOS clone showed significantly reduced adhesion to E-selectin compared with control cells (Figure 4A,

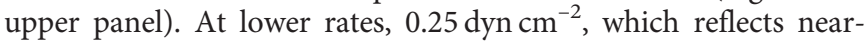
physiological conditions, enhanced c-FOS expression led to a strong and significant decrease in the number of adherent cells in both cell lines with values of $18-50 \%$ adherent cells as compared with controls.

The majority of selectin ligands consists of distinct glycan structures carrying the tetrasaccharides sialyl Lewis ${ }^{\mathrm{x} / \mathrm{a}}\left(\mathrm{sLe}^{\mathrm{x}} / \mathrm{sLe}^{\mathrm{a}}\right)$ on a protein backbone. We therefore checked the clones for expression of CA19-9 (sLe $\left.{ }^{a}\right)$ and CD15s (sLe ${ }^{\mathrm{x}}$ ) using flow cytometry. We detected high levels of both ligands in SKOV3 control cells, whereas c-FOS ${ }^{\text {high }}$ SKOV3 clones showed a strong to moderate reduction in the amount of CA19-9 and CD15s-positive cells, respectively (Figure 4B). In OVCAR8 cells, we did not detect expression of CA19-9 (data not shown) and CD15S (Figure 4B). The differential expression of CA19-9 in both cell lines and its reduction in c-FOS-overexpressing SKOV3 cells was also shown in western blot analysis (Supplementary Figure S2). Remarkably, cells
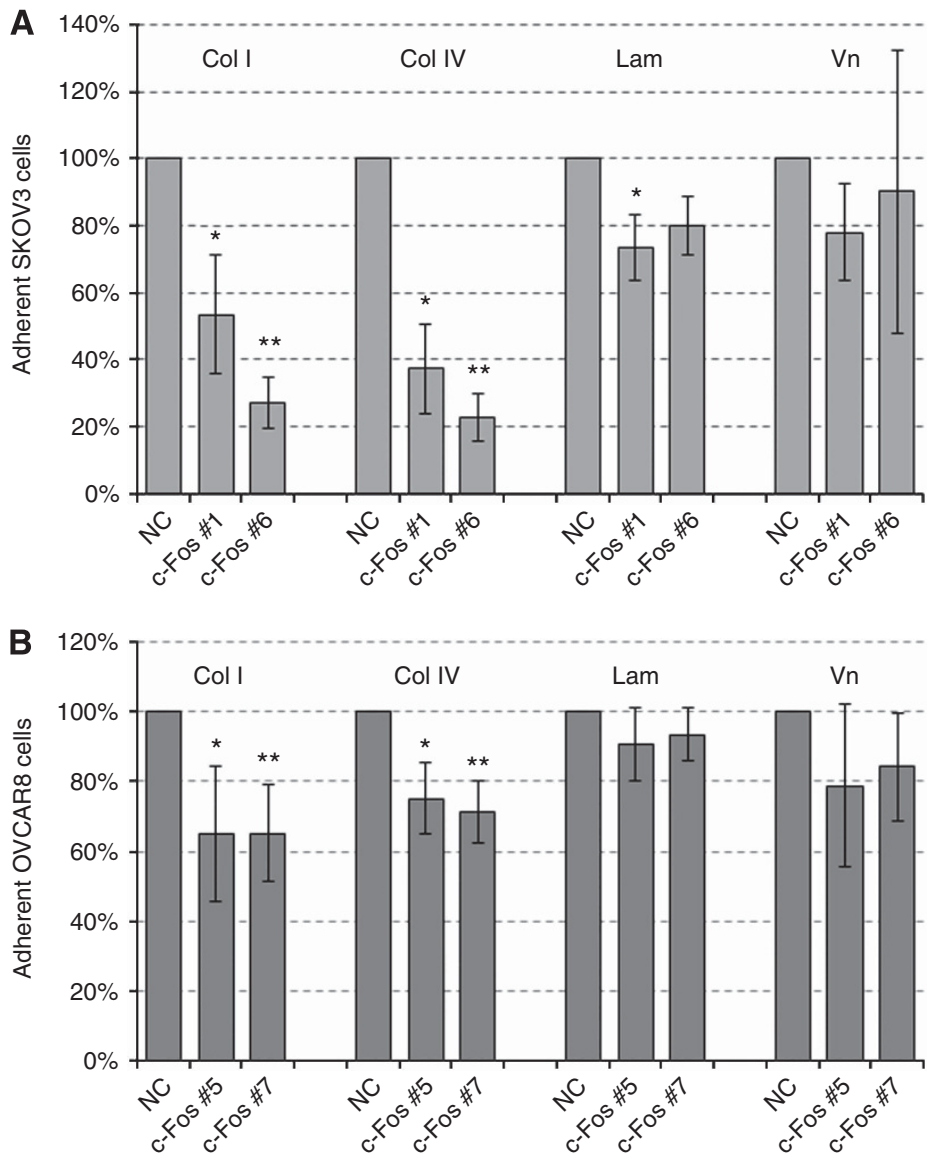
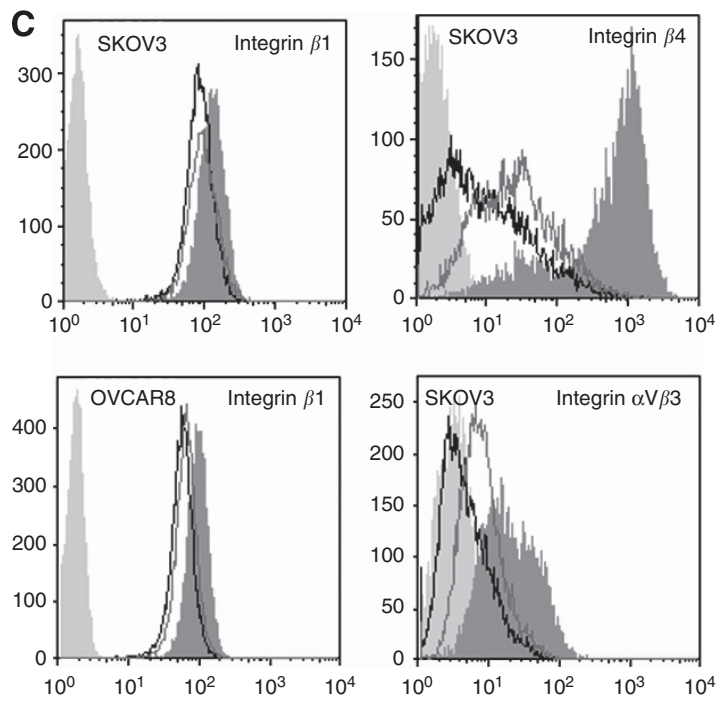

Figure 3. Influence of c-FOS expression on adhesion to collagen I, collagen IV, laminin and vitronectin in SKOV3 (A) and OVCAR8 cells (B). Percentages of adhesive cells relative to control \pm s.e.m. are shown. ${ }^{\star} P<0.05$; ${ }^{\star \star} P<0.01$. (C) Results of flow cytometry showing decreased integrin $\beta 1$ levels in SKOV3 and OVCAR8 cells (left panels) as well as reduction of integrin $\beta 4$ and $\alpha$ V $\beta 3$ levels in SKOV3 cells (right panels). 
A

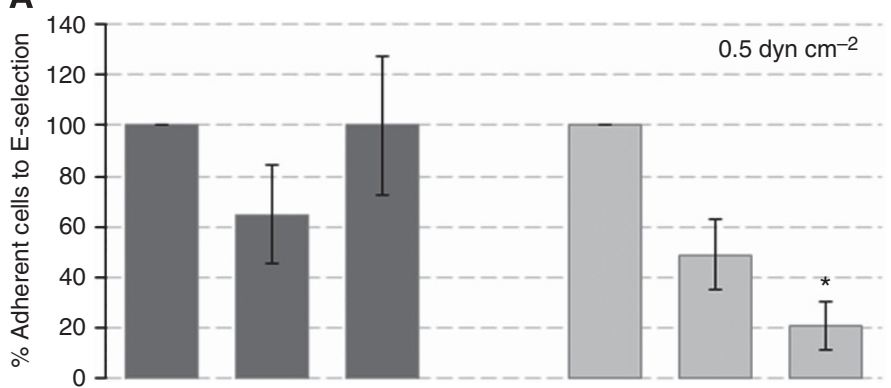

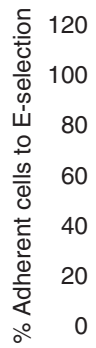

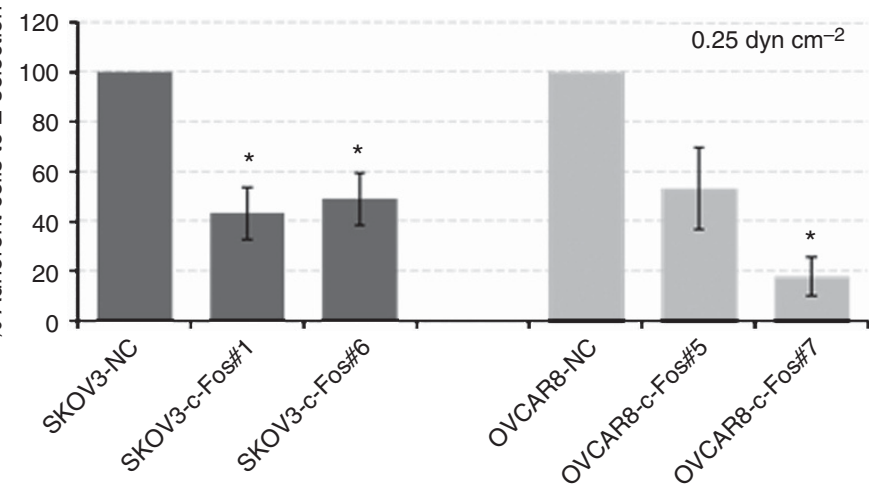

B
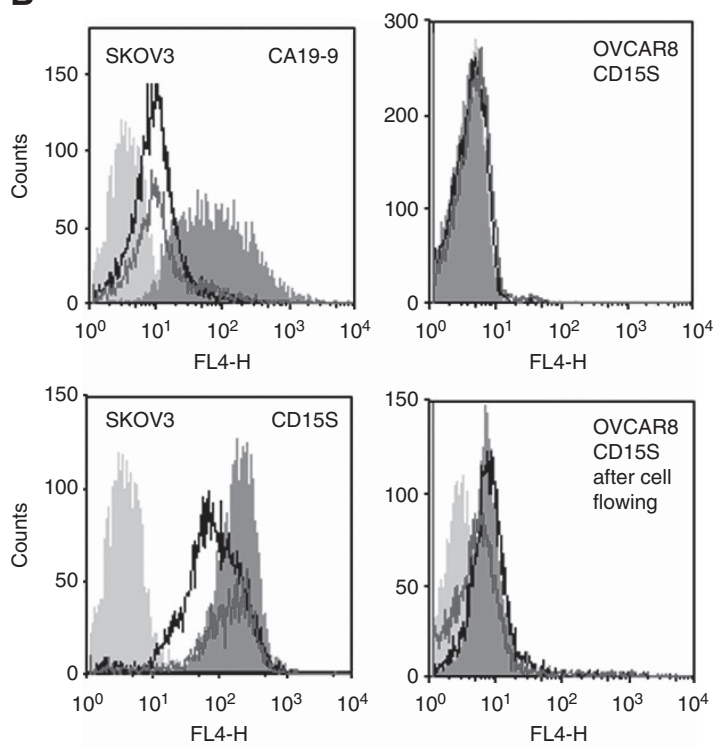

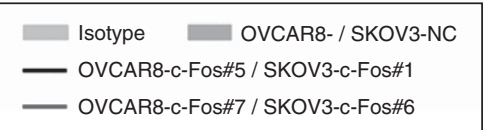

Figure 4. (A) Influence of c-FOS overexpression on adhesion to E-selectin in a dynamic cell-flow assay under different flow rates $(0.5$ and

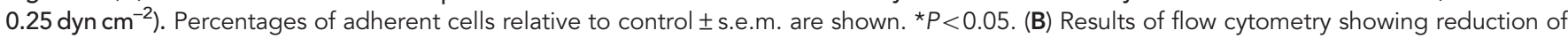
CA19-9 and CD15s in SKOV3-c-FOS cells (left panels). In OVCAR8 cells, weak expression of CD15s is shown only after shear stress (0.5 dyn $\mathrm{cm}^{-2}$; right panels).

became weakly positive for CD15S once they were subjected to shear forces, that is, after once flowing through the chamber at 0.5 dyn $\mathrm{cm}^{-2}$. Nevertheless, slight differences in CD15S levels compared with control cells were detected in only one OVCAR8 c-FOS $^{\text {high }}$ clone, suggesting that adhesion to E-selectin might be mainly mediated by other ligands in OVCAR8 cells.

c-FOS influences adhesion to endothelial and mesothelial cells. As c-FOS ${ }^{\text {high }}$ tumours showed less metastasis than those of control cells in the xenograft mouse model, we hypothesised that c-FOS overexpression might reduce adhesion of cancer cells to the endothelium or mesothelium. The latter seems to be particularly relevant, as OvCa cells primarily disseminate within the peritoneal cavity that is covered by a thin mesothelial cell layer.

Mimicking physiological conditions, we performed dynamic adhesion assays with capillaries that were coated with human endothelial or mesothelial cells. Stimulation with TNF $\alpha$ was performed before each assay, which had been found to upregulate several adhesion molecules in endothelial cells and to enhance attachment of tumour cells to the mesothelial monolayer (Murakami et al, 2000; Mochizuki et al, 2004; Dippel et al, 2012). In these experiments, SKOV3 exhibited strong adhesion to endothelial monolayers, whereas OVCAR8 cells rather demonstrated tethering behaviour. Nevertheless, all c-FOS ${ }^{\text {high }}$ cells evidenced reduced adhesion to activated HPMEC as compared with controls (Figure 5A). Although this difference was more pronounced at lower shear stress $\left(0.25 \mathrm{dyn} \mathrm{cm}^{-2}\right)$ for SKOV 3 cells, the influence of c-FOS on OVCAR8 adhesion was more evident at higher shear stress $\left(0.5 \mathrm{dyn}^{-2}\right)$.

Both tumour cell lines also showed adhesion to mesothelial cells at low shear stress. Namely, at $0.25 \mathrm{dyn}^{-2}$ SKOV3 clones with c-FOS overexpression exhibited less adhesion events than control cells $(P=0.07$; Figure $5 B)$. In contrast, we did not observe an effect of c-FOS on OVCAR8 adhesion under these conditions (data not shown). Only at a lower shear stress of $0.12 \mathrm{dyn} \mathrm{cm}^{-2}, \mathrm{c}^{-F O S} S^{\text {high }}$ clones showed slightly reduced adhesion to activated MES compared with controls.

Microarray analyses of c-FOS transfectants and validation of genes with dysregulated expression. In order to identify c-FOS target genes that could be involved in changing the adhesive properties of OvCa cells, we performed cDNA arrays with mRNA isolated from the stably transfected OvCa cell lines. mRNA isolated from xenograft tumour tissue (three tumours per group) was analysed as well (Supplementary Tables S2-S4). Genes that were increased or decreased at least two-fold compared with the respective control in both $\mathrm{c}-\mathrm{FOS}^{\text {high }}$ clones of one cell line were further considered as significantly dysregulated. Following this criteria, 561 and 124 genes were found to be upregulated and 674 and 255 genes downregulated in SKOV3-c-FOS clones and OVCAR8-c-FOS clones, respectively. We paid special attention to those genes that were commonly dysregulated in both c-FOS-overexpressing OVCAR8 and SKOV3 cells. We found 121 shared downregulated genes, and 37 common upregulated genes (Supplementary Table S5), many of which harbour AP-1-binding sites in their regulatory elements (data not shown). Interestingly, the first group included many genes related with adhesion and ECM modulation (Table 1). By qRT-PCR, the differential expression of some of these genes (AMIGO2, CDH11, FN1, TNC, VCAN and NPNT) could be confirmed. As aberrant glycosylation in cancer cells has been described to be relevant for tumour progression and metastasis, we checked the data for dysregulated genes related to this functional pathway. Many deregulated genes involved in $\mathrm{O}$ - and $\mathrm{N}$-glycosylation processes were found in SKOV3, but not in OVCAR8 clones. Using a qRT-PCR glycosylation array or qRT-PCR, we could validate c-FOS-mediated upregulation (B3GALTl, FUCA1, MAN1A1, GANAB and NEU1) and downregulation (CHST11, CHST15, FUT11, GALNT12, GALNT14, GCNT3 and ST6GAL1) of glycosylation enzymes (Table 1; 

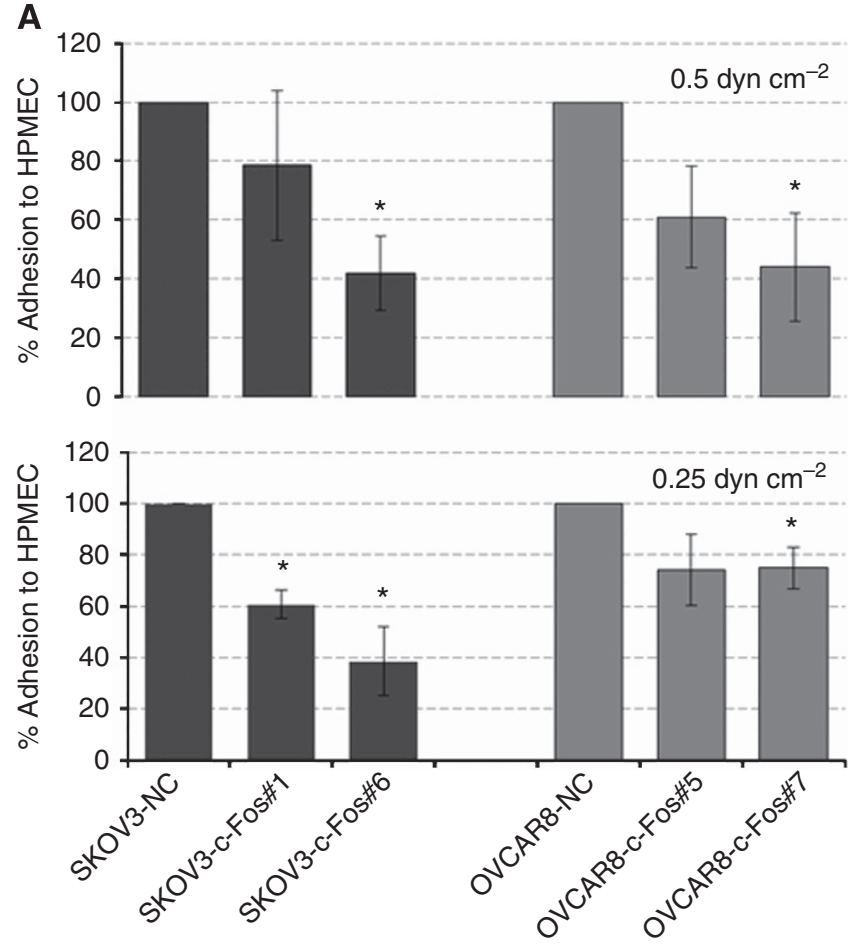

B

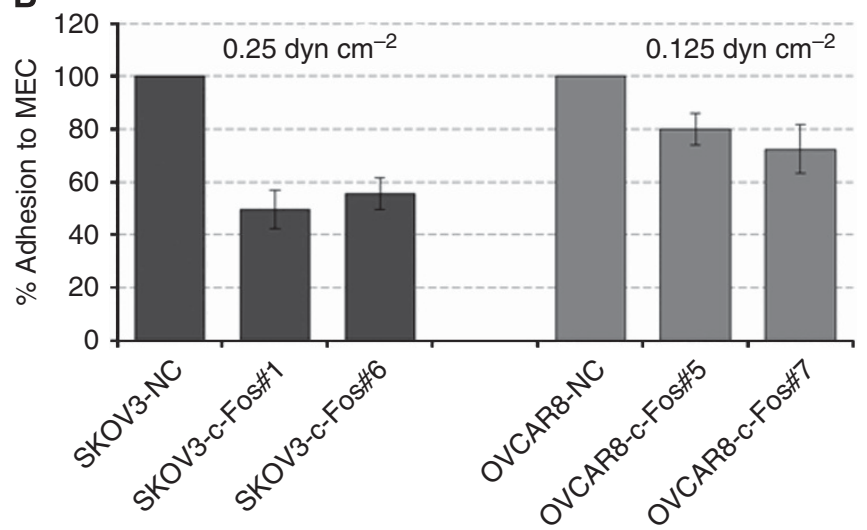

Figure 5. Influence of c-FOS overexpression on adhesion of SKOV3 and OVCAR8 cells to endothelial (A) and mesothelial cells (B) in dynamic adhesion assays with different flow rates. Percentages of adherent cells relative to control \pm s.e.m. are shown. ${ }^{\star} P<0.05$.

Supplementary data Supplementary Figure S2). Beta-integrins were also found to be downregulated in c-FOS ${ }^{\text {high }}$ cells. However, different subunit types were affected in the two cell lines, namely, ITGB3 and ITGB8 in OVCAR8 and ITGB5 and ITGB6 in SKOV3 (Table 1).

\section{DISCUSSION}

In a former study performed on clinical OvCa tissues, we found that c-FOS expression is associated with a significantly longer recurrence-free and overall survival (Mahner et al, 2008). The aim of the present experimental study was to elucidate the molecular mechanisms underlying these findings.

As a transcription factor of the AP-1 family, c-FOS regulates genes involved in multiple aspects of malignant progression, including proliferation (Angel and Karin, 1991), invasion (Hennigan et al, 1994), motility (Liu et al, 2006), angiogenesis
(Li et al, 2005), differentiation (Shafarenko et al, 2004) and apoptosis (Appierto et al, 2004). In addition, an influence of c-FOS on cell-cell and cell-matrix adhesion has been reported in murine mammary tumour cells (Mejlvang et al, 2007). However, little is known about the role of c-FOS in OvCa cells. Our present study adds another important effect of c-FOS expression that might influence tumour progression and metastasis in this entity: the ability to change the adhesive properties of cancer cells not only to ECM components but also to endothelial and mesothelial cells.

In order to explore the role of c-FOS in OvCa cells, we generated stable transfectants with forced c-FOS expression derived from two cell lines. Functional assays indicated that the influence of c-FOS on proliferation, migration and invasion is not likely to be responsible for its strong prognostic impact in OvCa (Mahner et al, 2008). In particular, the large differences in survival observed in the intraperitoneal xenograft mouse model between c-FOS ${ }^{\text {high }}$ and control SKOV3 cells cannot be explained by these processes.

In apoptosis assays, our results point to a strong positive influence of c-FOS on programmed cell death with or without addition of the anticancer drug camptothecin. The pro-apoptotic influence of c-FOS has been described in various cell types including OvCa cells (Appierto et al, 2004; Kalra and Kumar, 2004; Milde-Langosch, 2005; Zhang et al, 2007). In vivo, it might result in a higher sensitivity of c-FOS ${ }^{\text {high }}$ tumours towards chemotherapy. As all OvCa patients included in our prior study (Mahner et al, 2008) received a platin-based combination chemotherapy, we cannot determine if the positive influence of c-FOS on outcome is due to less aggressive tumour characteristics or to a changed response to chemotherapy. Yet, although the pro-apoptotic influence of c-FOS might be important for tumour progression in patients, it is unlikely to have a major role in our mouse model where c-FOS overexpression in injected tumour cells resulted in a strong delay of tumour growth and metastasis.

Ovarian cancer progression mainly takes place by intraperitoneal metastasis (Tan et al, 2006) that includes detachment from the primary tumour mass in a very early stage, dissemination in the peritoneal cavity caused by the constant flow of peritoneal fluid, escape from anoikis, adhesion of tumour cells or spheroids to the inner surface of the peritoneum and peritoneal implantation leading to the formation of metastatic tumours (Tan et al, 2006). In some cases, hematogenous spread takes place later. Thus, adhesion to the peritoneum might be a rate-limiting step in OvCa progression. Interestingly, a large group of c-FOS-regulated genes in both cell lines was involved in cell adhesion. This indicates that the tumour-suppressive impact of c-FOS might at least partly derive from changed adhesive properties. Our in vitro analyses support this hypothesis showing a remarkably decreased adhesion of c-FOS-overexpressing OvCa cells to diverse ECM components, E-selectin as well as to endothelial and mesothelial cells.

Selectin binding has been described as one of the crucial steps in the initial adhesion and homing of leukocytes and tumour cells (von Andrian and Mackay, 2000; Tremblay et al, 2008). Several studies have shown selectin expression on endothelial cells and as recently shown, also on mesothelial cells (Gebauer et al, 2012). Our present data show that E-selectin binding is significantly reduced in c-FOS-overexpressing OvCa cells under flow conditions. In SKOV3, this might be mainly due to reduced levels of the E-selectin ligands sialyl Lewis $\mathrm{X}(\mathrm{CD} 15 \mathrm{~s})$ and sialyl Lewis A (CA19-9) as shown in FACS analysis. As in OVCAR8 cells only minimal expression of these ligands was detectable, alternative selectin ligands have to be postulated. Interestingly, some enzymes involved in O-glycosylation and the generation of Lewis antigens (FUT11, GNCT3 and GALNT14) are downregulated in SKOV3, but not OVCAR8 cells. Similarly, the O-glycan degrading fucosidase FUCA1 was upregulated in c-FOS-overexpressing SKOV3 cells only. This might explain the differences in sialyl Lewis ${ }^{\mathrm{a} / \mathrm{x}}$ levels between both cell lines shown in FACS analysis. Regarding the 
Fold change

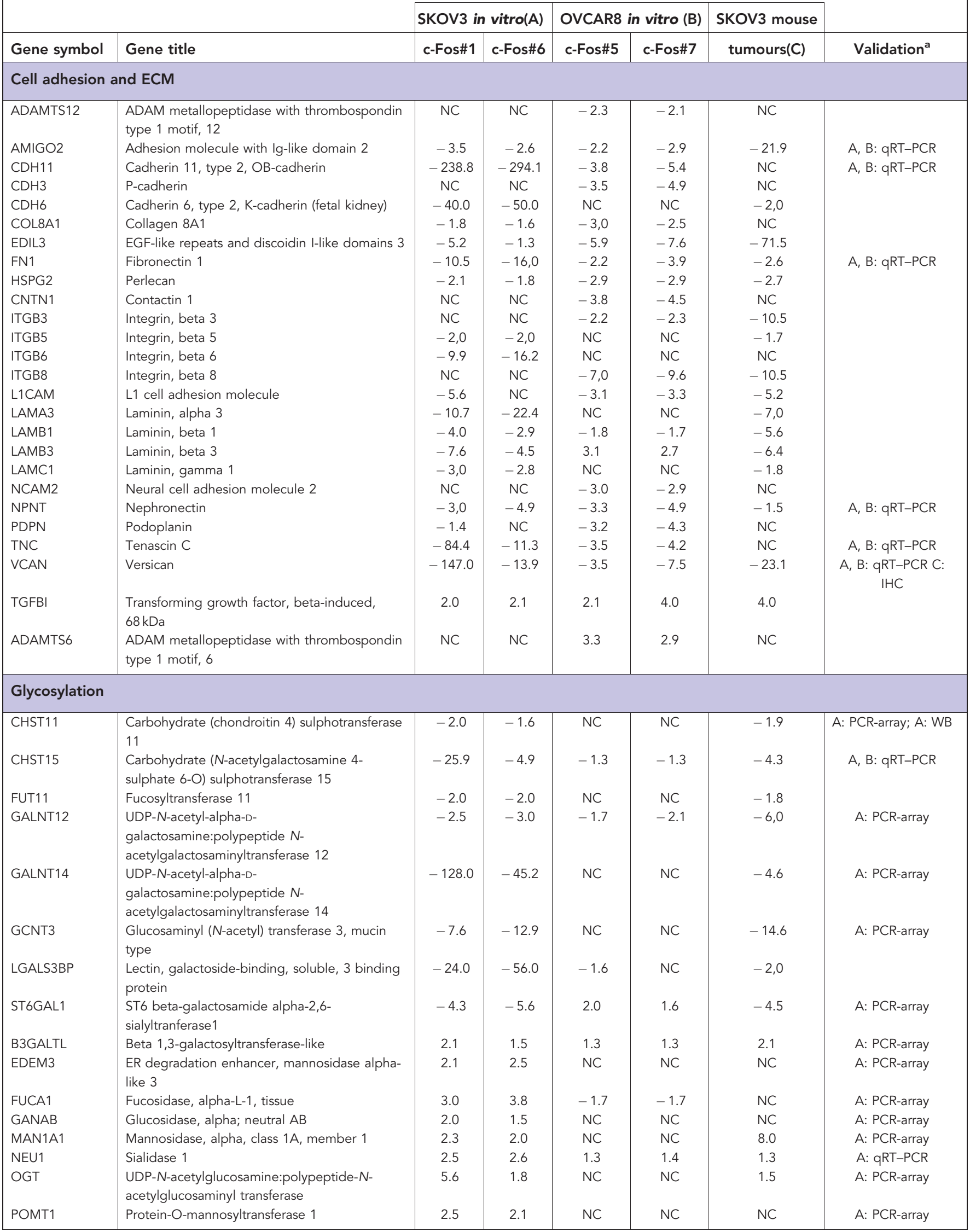


Fold change

\begin{tabular}{|c|c|c|c|c|c|c|c|}
\hline \multirow[b]{3}{*}{ Gene symbol } & \multirow[b]{3}{*}{ Gene title } & \multicolumn{5}{|c|}{ Fold change } & \multirow[b]{3}{*}{ Validation $^{a}$} \\
\hline & & \multicolumn{2}{|c|}{ SKOV3 in vitro(A) } & \multicolumn{2}{|c|}{ OVCAR8 in vitro (B) } & \multirow{2}{*}{$\begin{array}{c}\text { SKOV3 mouse } \\
\text { tumours(C) }\end{array}$} & \\
\hline & & c-Fos\#1 & c-Fos\#6 & c-Fos\#5 & c-Fos\#7 & & \\
\hline \multicolumn{8}{|c|}{ Invasion and others } \\
\hline $\begin{array}{l}\text { PLAU } \\
\text { MMP1 } \\
\text { MMP16 }\end{array}$ & $\begin{array}{l}\text { Plasminogen activator, urokinase } \\
\text { Matrix metalloproteinase } 1 \\
\text { Matrix metalloproteinase } 16\end{array}$ & $\begin{array}{l}-8.0 \\
-3.5 \\
-2.8\end{array}$ & $\begin{array}{l}-6.9 \\
-5.1 \\
-1.6\end{array}$ & $\begin{array}{c}\mathrm{NC} \\
25.6 \\
2.0\end{array}$ & $\begin{array}{c}-1.6 \\
26.2 \\
2.0\end{array}$ & $\begin{array}{l}-1.3 \\
-1.9 \\
-2.9\end{array}$ & A: ELISA \\
\hline $\begin{array}{l}\text { CPA4 } \\
\text { SERPINB2 }\end{array}$ & $\begin{array}{l}\text { Carboxypeptidase A4 } \\
\text { Serpin peptidase inhibitor, clade B (ovalbumin), } \\
\text { member } 2 / 10\end{array}$ & $\begin{array}{l}2.8 \\
\mathrm{NC}\end{array}$ & $\begin{array}{l}4.4 \\
\mathrm{NC}\end{array}$ & $\begin{array}{c}-10.4 \\
62.3\end{array}$ & $\begin{array}{c}-12.8 \\
51.5\end{array}$ & $\begin{array}{c}58.3 \\
2.3\end{array}$ & \\
\hline $\begin{array}{l}\text { SPP1 } \\
\text { TNIK }\end{array}$ & $\begin{array}{l}\text { Secreted phosphoprotein } 1 \text { (osteopontin) } \\
\text { TRAF2 and NCK interacting kinase }\end{array}$ & $\begin{array}{c}-344.0 \\
-7.5\end{array}$ & $\begin{array}{l}-242.0 \\
-11.4\end{array}$ & $\begin{array}{l}\mathrm{NC} \\
-2.9\end{array}$ & $\begin{array}{l}N C \\
-3.4\end{array}$ & $\begin{array}{l}-73.0 \\
-2.4\end{array}$ & $\begin{array}{c}\text { A: WB } \\
A, B: \text { qRT-PCR }\end{array}$ \\
\hline
\end{tabular}

Abbreviations: $E C M=$ extracellular matrix; ELISA = enzyme-linked immunosorbent assay; $F C=$ fold change; $I H C=$ immunohistochemistry; $N C=$ no change $(F C<1.3) ; q R T-P C R=$ quantitative reverse transcriptase-PCR; WB = western blots. For results of validation see Supplementary Figure S1.

${ }^{\mathrm{a}} \mathrm{A}$ : SKOV3 in vitro; B: OVCAR8 in vitro; C: SKOV3 mouse tumours.

results of our microarray analysis, c-FOS expression not only leads to reduced O-glycosylation (see above), but also to downregulation of the chondroitin sulphotransferases CHST11 and CHST15. This might result in reduced levels of chondroitin sulphate proteoglycans, which were reported to act as selectin ligands (MonzaviKarbassi et al, 2007). The protein backbone of some of these glycosaminoglycans, versican and perlecan, was also downregulated by c-FOS in both cell lines. Which of the alternative selectin ligands, that is, chondroitin sulphate of glycolipids, are affected by c-FOS overexpression in OVCAR8 cells, cannot be answered to date. Nevertheless, CHST15, a gene encoding a type II transmembrane glycoprotein that transfers sulphate to the C-6 hydroxal group of chondroitin sulphate, was downregulated in c-Fosoverexpressing OVCAR8 cells.

A potential reason for the differences in c-FOS-regulated genes in both cell lines are varying basal expression levels of specific genes, probably based on different genetic backgrounds. Regarding the results of our microarray analysis, many adhesion enzymes were much more highly expressed in SKOV3-NC compared with OVCAR8-NC cells, that is, the integrins $I T G \alpha 2, I T G \beta 3, I T G \beta 6$ as well as the glycosylation enzymes GCNT3, ST3GAL6 and ST6GAL1 (data not shown). This allows a more effective downregulation by c-FOS in SKOV3 cells.

Reduced adhesion of c-FOS ${ }^{\text {high }}$ cells to endothelial or mesothelial layers might not only be due to less binding to selectins, as mentioned above, but also to members of the integrin family. Integrins follow selectins in the adhesion cascade of leukocytes, and cancer cells use similar adhesion mechanisms (Strell and Entschladen, 2008). Various integrin-binding proteins like laminins, collagens, fibronectin, osteopontin, tenascin C and EDIL3 are less expressed in $\mathrm{c}^{-F O S^{\text {high }}}$ OvCa cells. Regarding adhesion proteins of the immunoglobulin superfamily, L1-CAM is downregulated in c-FOS ${ }^{\text {high }}$ cells. In a prior study, we could show that L1-CAM is involved in adhesion of breast cancer cells to endothelial cells (Dippel et al, 2012).

In addition to adherence to the mesothelium, adhesion to components of the underlying ECM takes place in peritoneal metastasis. Mesothelial cells do not always form a continuous cell layer, but are interrupted by 'milky spots' (Shimotsuma et al, 1989), influenced by cytokines ( $\mathrm{Na}$ et al, 2010) and undergo morphological changes after contact with tumour cells leading to exposure of ECM components (Iwanicki et al, 2011). In static adhesion assays, we found significantly reduced adhesion of c-FOS ${ }^{\text {high }}$ cells to collagen I and IV, and a weaker influence on adhesion to vitronectin and laminin. This suggests that c-FOS regulates adhesion of OvCa cells not only to the mesothelium, but also to underlying stromal components, potentially by reduced integrin levels. By flow cytometry, we found c-FOSinduced reduction of integrin $\beta 1$ levels in both cell lines, which might partly be responsible for diminished collagen binding. Reduction of integrin $\beta 4$ was only observed in SKOV3, corresponding to the more pronounced effect of c-FOS on laminin binding compared with OVCAR8 cells. In contrast, the clear reduction of $\alpha \mathrm{V} \beta 3$ dimers in c-FOS-overexpressing SKOV3 clones does not correspond to the low or absent differences in vitronectin or fibronectin binding suggesting the use of multiple redundant receptors to mediate interactions with this ECM protein as previously reported for other cell types (WelserAlves et al, 2011). Yet, the results of our microarray analysis suggest that additional integrins like $\beta 5, \beta 6$ or $\beta 8$ might also be involved in altered adhesion to ECM proteins. Additional adhesion assays including blocking antibodies against specific integrins would be necessary to fully elucidate the molecular mechanism of reduced ECM binding in c-FOS-overexpressing OvCa cells.

A limitation of our study is the lack of experiments exploring the effects of c-FOS silencing in OvCa cells. Yet, our approach trying to establish OvCa cell clones with stable c-FOS downregulation by shRNA failed, similar to experiences published by others (Wen et al, 2007). The probable reason is an autoregulatory mechanism ensuring certain levels of endogenous c-FOS expression in the cells (König et al, 1989). How this autoregulation is undercut in OvCa cell lines with very low c-FOS expression remains to be analysed.

In conclusion, our data suggest that c-FOS inhibits metastasis in OvCa by modulating the adhesive properties of OvCa cells. This might also underlie the favourable prognosis of OvCa patients whose tumours show higher c-FOS expression. Our findings do not exclude the possibility that under in vivo conditions, the proapoptotic effect of c-FOS might also influence the outcome of chemotherapy-treated patients, which is obviously irrelevant in the SCID mouse model. The functional relevance of single c-FOSregulated genes for adhesion of OvCa cells to the peritoneum will be analysed in future works. A deeper knowledge of the molecular mechanisms regulating peritoneal metastasis might be important for the development of new therapeutic strategies in OvCa.

\section{ACKNOWLEDGEMENTS}

We are grateful to the excellent technical assistance of Maila Rossberg, Kathrin Eylmann, Christine Knies and Susanne 
Feldhaus. In addition, we thank Dr Martina Vetter (Halle, Germany) for uPA ELISA, Dr Tobias Lange for his help with PCR arrays and Dr Christine zu Eulenburg for statistical consulting. For taking part in microarray experiments, we appreciate the help of Dr Thomas Streichert and Kristin Klätschke (Hamburg, Germany) as well as Dr VV Galatenko and AE Lebedev (Moscow) for the processing of microarray data, SV Vinogradova for the help with pathway analysis. This study was supported by a grant from the 'Johanna und Fritz Buch Gedächtnis-Stiftung' to KM-L and FJ. For financial support of microarray analysis and German-Russian cooperation to US and AT, we thank the Bundesministerium für Bildung und Forschung (BMBF no. RUS 10/022) and Russian Ministry of Science Contracts (no. 16.522.11.2004).

\section{REFERENCES}

Angel P, Karin M (1991) The role of Jun, Fos and the AP-1 complex in cell-proliferation and transformation. Biochim Biophys Acta 1072(2-3): 129-157.

Appierto V, Villani MG, Cavadini E, Lotan R, Vinson C, Formelli F (2004) Involvement of c-Fos in fenretinide-induced apoptosis in human ovarian carcinoma cells. Cell Death Differ 11(3): 270-279.

Barthel SR, Gavino JD, Descheny L, Dimitroff CJ (2007) Targeting selectins and selectin ligands in inflammation and cancer. Expert Opin Ther Targets 11(11): 1473-1491.

Dippel V, Milde-Langosch K, Wicklein D, Schumacher U, Altevogt P, Oliveira-Ferrer L, Janicke F, Schroder C (2012) Influence of L1-CAM expression of breast cancer cells on adhesion to endothelial cells. J Cancer Res Clin Oncol 139(1): 107-121.

Durchdewald M, Angel P, Hess J (2009) The transcription factor Fos: a Janus-type regulator in health and disease. Histol Histopathol 24(11): 1451-1461.

Gamberi G, Benassi MS, Bohling T, Ragazzini P, Molendini L, Sollazzo MR, Pompetti F, Merli M, Magagnoli G, Balladelli A, Picci P (1998) C-myc and c-fos in human osteosarcoma: prognostic value of mRNA and protein expression. Oncology 55: 556-563.

Gebauer F, Wicklein D, Stubke K, Nehmann N, Schmidt A, Salamon J, Peldschus K, Nentwich MF, Adam G, Tolstonog G, Bockhorn M, Izbicki JR, Wagener C, Schumacher U (2012) Selectin binding is essential for peritoneal carcinomatosis in a xenograft model of human pancreatic adenocarcinoma in pfp-/rag2- mice. Gut 62: 741-750.

Guinea-Viniegra J, Zenz R, Scheuch H, Jimenez M, Bakiri L, Petzelbauer P, Wagner EF (2012) Differentiation-induced skin cancer suppression by FOS, p53, and TACE/ADAM17. J Clin Invest 122(8): 2898-2910.

Hein S, Mahner S, Kanowski C, Löning T, Jänicke F, Milde-Langosch K (2009) Expression of Jun and Fos proteins in ovarian tumors of different malignant potential and in ovarian cancer cell lines. Oncol Rep 22(1): 177-183.

Hennigan RF, Hawker KL, Ozanne BW (1994) Fos-transformation activates genes associated with invasion. Oncogene 9(12): 3591-3600.

Iwanicki MP, Davidowitz RA, Ng MR, Besser A, Muranen T, Merritt M, Danuser G, Ince TA, Brugge JS (2011) Ovarian cancer spheroids use myosin-generated force to clear the mesothelium. Cancer Discov 1(2): 144-157.

Jänicke F, Pache L, Schmitt M, Ulm K, Thomssen C, Prechtl A, Graeff H (1994) Both the cytosols and detergent extracts of breast cancer tissues are suited to evaluate the prognostic impact of the urokinase-type plasminogen activator and its inhibitor, plaminogen activator inhibitor type I. Cancer Res 54: 2527-2530.

Jin SP, Kim JH, Kim MA, Yang HK, Lee HE, Lee HS, Kim WH (2007) Prognostic significance of loss of c-fos protein in gastric carcinoma. Pathol Oncol Res 13(4): 284-289.

Jojovic M, Schumacher U (2000) Quantitative assessment of spontaneous lung metastases of human HT29 colon cancer cells transplanted into scid mice. Cancer Lett 152: 151-156.

Kalra N, Kumar V (2004) c-Fos is a mediator of the c-myc-induced apoptotic signaling in serum-deprived hepatoma cells via the p38 mitogen-activated protein kinase pathway. J Biol Chem 279(24): 25313-25319.

König H, Ponta H, Rahmsdorf U, Buscher M, Schonthal A, Rahmsdorf HJ, Herrlich P (1989) Autoregulation of fos: the dyad symmetry element as the major target of repression. EMBO J 8(9): 2559-2566.
Kustikova O, Kramerov D, Grigorian M, Berezin V, Bock E, Lukanidin E, Tulchinsky E (1998) Fra-1 induces morphological transformation and increases in vitro invasiveness and mobility of epithelioid adenocarcinoma cells. Mol Cell Biol 18: 7095-7105.

Lange T, Ullrich S, Muller I, Nentwich MF, Stubke K, Feldhaus S, Knies C, Hellwinkel OJ, Vessella RL, Abramjuk C, Anders M, Schroder-Schwarz J, Schlomm T, Huland H, Sauter G, Schumacher U (2012) Human prostate cancer in a clinically relevant xenograft mouse model: identification of beta $(1,6)$-branched oligosaccharides as a marker of tumor progression. Clin Cancer Res 18(5): 1364-1373.

Li YQ, Tao KS, Ren N, Wang YH (2005) Effect of c-fos antisense probe on prostaglandin E2-induced upregulation of vascular endothelial growth factor mRNA in human liver cancer cells. World J Gastroenterol 11(28): 4427-4430.

Liu G, Ding W, Liu X, Mulder KM (2006) c-Fos is required for TGFbeta1 production and the associated paracrine migratory effects of human colon carcinoma cells. Mol Carcinog 45(8): 582-593.

Liu G, Takano T, Matsuzuka H, Higashiyama T, Kuma K, Amino N (1999) Screening of specific changes in mRNAs in thyroid tumors by sequence specific differential display: decreased expression of c-Fos mRNA in papillary carcinoma. Endocr J 46: 459-466.

Mahner S, Baasch C, Schwarz J, Hein S, Wolber L, Janicke F, Milde-Langosch K (2008) C-Fos expression is a molecular predictor of progression and survival in epithelial ovarian carcinoma. Br J Cancer 99(8): 1269-1275.

Meinhold-Heerlein I, Bauerschlag D, Hilpert F, Dimitrov P, Sapinoso LM, Orlowska-Volk M, Bauknecht T, Park T-W, Jonat W, Jacobsen A, Sehouli J, Luttges J, Krajewski M, Krajewski S, Reed JC, Arnold N, Hampton GM (2005) Molecular and prognostic distinction between serous ovarian carcinomas of varying grade and malignant potential. Oncogene 24: 1053-1065.

Mejlvang J, Kriajevska M, Berditchevski F, Bronstein I, Lukanidin EM, Pringle JH, Mellon JK, Tulchinsky EM (2007) Characterization of E-cadherin-dependent and -independent events in a new model of c-Fos-mediated epithelial-mesenchymal transition. Exp Cell Res 313(2): 380-393.

Mikula M, Gotzmann J, Fischer A, Wolschek MF, Thallinger C, Schulte-Hermann R, Beug H, Mikulits W (2003) The proto-oncogene c-Fos negatively regulates hepatocellular tumorigenesis. Oncogene 22: 6725-6738.

Milde-Langosch K (2005) The Fos family of transcription factors and their role in tumourigenesis. Eur J Cancer 41(16): 2449-2461.

Miller DA, Curran T, Verma IM (1984) c-fos protein can induce cellular transformation: a novel mechanism of a cellular oncogene. Cell 36: 51-60.

Mochizuki Y, Nakanishi H, Kodera Y, Ito S, Yamamura Y, Kato T, Hibi K, Akiyama S, Nakao A, Tatematsu M (2004) TNF-alpha promotes progression of peritoneal metastasis as demonstrated using a green fluorescence protein (GFP)-tagged human gastric cancer cell line. Clin Exp Metastasis 21(1): 39-47.

Monzavi-Karbassi B, Stanley JS, Hennings L, Jousheghany F, Artaud C, Shaaf S, Kieber-Emmons T (2007) Chondroitin sulfate glycosaminoglycans as major P-selectin ligands on metastatic breast cancer cell lines. Int J Cancer 120(6): 1179-1191.

Murakami T, Mataki C, Nagao C, Umetani M, Wada Y, Ishii M, Tsutsumi S, Kohro T, Saiura A, Aburatani H, Hamakubo T, Kodama T (2000) The gene expression profile of human umbilical vein endothelial cells stimulated by tumor necrosis factor alpha using DNA microarray analysis. J Atheroscler Thromb 7(1): 39-44.

Na D, Lv ZD, Liu FN, Xu Y, Jiang CG, Sun Z, Miao ZF, Li F, Xu HM (2010) Transforming growth factor betal produced in autocrine/paracrine manner affects the morphology and function of mesothelial cells and promotes peritoneal carcinomatosis. Int J Mol Med 26(3): 325-332.

Nandy A, Jenatschke S, Hartung B, Milde-Langosch K, Bamberger AM, Gellersen B (2003) Genomic structure and transcriptional regulation of the human NAD + -dependent 15-hydroxyprostaglandin dehydrogenase gene. $J$ Mol Endocrinol 31(1): 105-121.

Oliveira-Ferrer L, Wellbrock J, Braig M, Klokow M, Hauschild J, Bokemeyer C, Fiedler W, Ergun S, Schuch G (2012) The metabolite 3-hydroxiglutaric acid effectively reduces glioblastoma growth in vivo by affecting the structural integrity of tumor vasculature. Cancer Lett 326(2): 161-167.

Richter U, Schroder C, Wicklein D, Lange T, Geleff S, Dippel V, Schumacher U, Klutmann S (2011) Adhesion of small cell lung cancer cells to E- and P-Selectin under physiological flow conditions: implications for metastasis formation. Histochem Cell Biol 135(5): 499-512. 
Rüther U, Komitowski D, Schubert FR, Wagner EF (1989) c-Fos expression induces bone tumors in transgenic mice. Oncogene 4: 861-865.

Schröder C, Schumacher U, Müller V, Wirtz RM, Streichert T, Richter U, Wicklein D, Milde-Langosch K (2010) The transcription factor Fra-2 promotes mammary tumour progression by changing the adhesive properties of breast cancer cells. Eur J Cancer 46(9): 1650-1660.

Shafarenko M, Amanullah A, Gregory B, Liebermann DA, Hoffman B (2004) Fos modulates myeloid cell survival and differentiation and partially abrogates the c-Myc block in terminal myeloid differentiation. Blood 103(11): 4259-4267.

Shaulian E, Karin M (2001) AP-1 in cell proliferation and survival. Oncogene 20(19): 2390-2400.

Shimotsuma M, Kawata M, Hagiwara A, Takahashi T (1989) Milky spots in the human greater omentum. Macroscopic and histological identification. Acta Anat (Basel) 136(3): 211-216.

Silvestre DC, Gil GA, Tomasini N, Bussolino DF, Caputto BL (2010) Growth of peripheral and central nervous system tumors is supported by cytoplasmic c-Fos in humans and mice. PLoS One 5(3): e9544.

Strell C, Entschladen F (2008) Extravasation of leukocytes in comparison to tumor cells. Cell Commun Signal 6: 10.

Stübke K, Wicklein D, Herich L, Schumacher U, Nehmann N (2012) Selectin-deficiency reduces the number of spontaneous metastases in a xenograft model of human breast cancer. Cancer Lett 321(1): 89-99.

Tan DS, Agarwal R, Kaye SB (2006) Mechanisms of transcoelomic metastasis in ovarian cancer. Lancet Oncol 7(11): 925-934.

Tremblay PL, Huot J, Auger FA (2008) Mechanisms by which E-selectin regulates diapedesis of colon cancer cells under flow conditions. Cancer Res 68(13): 5167-5176.
Volm M, Koomägi R, Mattern J, Efferth T (2002) Expression profile of genes in non-small cell lung carcinomas from long-term surviving patients. Clin Cancer Res 8: 1843-1848.

von Andrian UH, Mackay CR (2000) T-cell function and migration. Two sides of the same coin. N Engl J Med 343(14): 1020-1034.

Welser-Alves JV, Boroujerdi A, Tigges U, Milner R (2011) Microglia use multiple mechanisms to mediate interactions with vitronectin; nonessential roles for the highly-expressed alphavbeta3 and alphavbeta5 integrins. J Neuroinflammation 8: 157.

Wen W, Iwakiri D, Yamamoto K, Maruo S, Kanda T, Takada K (2007) Epstein-Barr virus BZLF1 gene, a switch from latency to lytic infection, is expressed as an immediate-early gene after primary infection of B lymphocytes. J Virol 81(2): 1037-1042.

Workman P, Aboagye EO, Balkwill F, Balmain A, Bruder G, Chaplin DJ, Double JA, Everitt J, Farningham DA, Glennie MJ, Kelland LR, Robinson V, Stratford IJ, Tozer GM, Watson S, Wedge SR, Eccles SA (2010) Guidelines for the welfare and use of animals in cancer research. Br J Cancer 102(11): 1555-1577.

Zhang X, Zhang L, Yang H, Huang X, Otu H, Libermann TA, DeWolf WC, Khosravi-Far R, Olumi AF (2007) c-Fos as a proapoptotic agent in TRAILinduced apoptosis in prostate cancer cells. Cancer Res 67(19): 9425-9434.

This work is published under the standard license to publish agreement. After 12 months the work will become freely available and the license terms will switch to a Creative Commons AttributionNonCommercial-Share Alike 3.0 Unported License.

Supplementary Information accompanies this paper on British Journal of Cancer website (http://www.nature.com/bjc) 